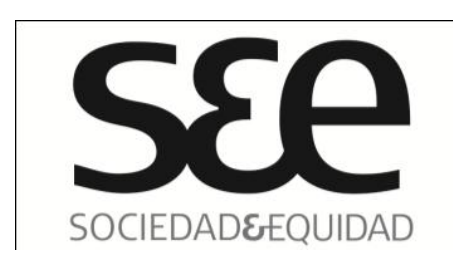

\title{
Tortura en la dictadura chilena: la segregación de la anestesia
}

\author{
Torture in the Chilean dictatorship: segregation of \\ anesthesia
}

\begin{abstract}
Nombre:
Filiación:

País:
\end{abstract}

Correo:

\author{
Valeria Osorio Ureta ( $\left.{ }^{1}\right)$ \\ Universidad de Chile \\ Chile \\ valeria.osorio.ureta@gmail.com
}

\section{RESUMEN}

El presente ensayo tiene por finalidad ofrecer algunas nociones referentes a la tortura y su institucionalización como método de control durante la dictadura militar chilena. Se hace una reflexión de la experiencia de la Universidad Técnica del Estado entre 1973-1990, para lo que se consideran algunos testimonios y descripciones de lo ocurrido al interior de este plantel educacional, que permiten articular los conceptos de tortura, anestesia y Derechos Humanos. De este trabajo se desprende que las dictaduras militares se valen del uso de la fuerza y de las prácticas coercitivas para institucionalizarse, violando sistemática los Derechos Humanos. Además, el posicionamiento de un nuevo modelo, requiere generar un daño profundo que haga un quiebre con la anterior institucionalidad, permitiéndole afectar los más diversos espacios de la vida, los cuerpos y su movilidad. Finalmente, es importante recordar estos trances, revivir estos cuerpos y darles un hálito de vida para que al menos exista un registro de su tránsito por este país.

\section{ABSTRACT}

This paper is intended to provide some insight concerning torture and its institutionalization as a means of control during the Chilean military dictatorship. Experiences that took place at the Universidad Técnica del Estado between 19731990 are discussed. Testimonials and descriptions of what happened inside this site of education are considered, in order to articulate the concepts of torture, anesthesia and Human Rights. This work shows that military dictatorships rely on the use of force and coercive practices in order to become institutionalized,

\footnotetext{
${ }^{1}$ La autora es Licenciada en Comunicación Social, Periodista de la Universidad de Santiago. Actualmente cursa el Magister en Comunicación Política de la Universidad de Chile. Sus líneas investigativas de especialización son: Participación política y juventud.
} 


\section{SEe}

systematically violating Human Rights. Furthermore, the positioning of a new model requires the generation of a deep damage in order to break out with old institutions. Therefore, affecting various areas of life, bodies and their mobility. Finally, it is important to remember these trances, so we can revive these bodies and give them a breath of life, so that there is at least a record of their journey through this country.

PALABRAS CLAVES: Tortura, anestesia, Derechos Humanos.

KEYWORDS: Torture, anesthesia, human rights.

\section{Introducción}

Este trabajo nace bajo una necesidad personal de rescatar, reconocer y aclarar ideas e historias que giraron en torno a la traumática experiencia dictatorial acaecida en Chile a partir del 11 de septiembre de 1973, y la cual se extendió hasta el 11 de marzo de 1990. En ese contexto, la Universidad Técnica del Estado (UTE) constituyó algo más que un mero espacio académico; fue también el centro depositario de proyectos e ideales, asumidos y reconocidos por la sociedad chilena. Los acontecimientos la convirtieron en víctima de un régimen vertiginoso e inagotable, que no dudó en aplicar sus mayores argucias para reducirla y enrielarla.

La UTE sufrió múltiples intentos de aniquilación. Borraron su nombre, la redujeron a su mínima expresión a partir de 1981 con la Ley General de Universidades, quitándole sus ocho sedes regionales de Antofagasta, Copiapó, La Serena, Talca, Concepción, Temuco, Valdivia y Punta Arenas. A lo anterior, se sumó el deseo de extirpar el germen marxista de sus aulas. A pesar de esto, la USACH (nombre que recibiría la Universidad Técnica del Estado a partir de 1981) aún alberga en sus patios los nombres de personas que deben mantenerse vivas en la memoria no solo institucional sino también del país.

Este trabajo esboza en sus líneas la lógica bajo la cual se sustenta una dictadura, la que para validarse utiliza una serie de artilugios prácticos y legales para conseguir su fin: la imposición del modelo y del pensamiento, utilizando la tortura. Inicialmente, se exponen ideas del francés Michel Foucault para comprender la lógica de funcionamiento del poder soberano al derecho a la vida o la muerte. Posteriormente, se esboza el instrumento por excelencia para cooptar los cuerpos: la tortura, describiendo algunos ejemplos y casos de estudiantes de la UTE. Finalmente, se presenta el concepto de anestesia trabajado por el filósofo francés Alain Brossat, estableciendo la segregación que se realiza en torno a la aplicación de ésta. La ausencia del método anestésico concentra y exacerba el dolor en determinados cuerpos, mientras en otros su aplicación provoca un constante adormecimiento e incapacidad de generar una respuesta a acciones vejatorias. 


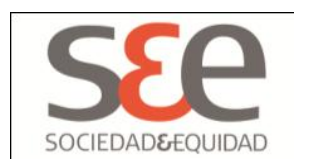

\section{Desarrollo}

El cuerpo no forma solo parte de la biología y sus teorías de la evolución y origen de las especies, sino que se ha incorporado como pieza relevante de estudios que buscan comprender el orden social y las diferentes dinámicas que se dan en las sociedades, incluyendo los episodios negativos, como lo son las dictaduras.

La coacción de los cuerpos y el sometimiento de éstos, fue un secreto a voces durante el régimen militar que se extendió en Chile entre el 11 de septiembre de 1973 y comienzos de 1990. La dictadura encabezada por el General en Jefe del Ejército, Augusto Pinochet Ugarte, marcó una etapa negra compleja en la historia local y regional. Sin duda, esta compleja etapa fue propiciada a través de una serie de herramientas que hicieron factible la permanencia de un régimen autoritario, el cual se enmarca -en cierto modo- en el paradigma inmunitario que trabaja Roberto Esposito (Esposito, 2005), en el sentido de que las garantías de las personas están vinculadas y entrelazadas con el derecho y la disciplina de los propios cuerpos, que en mayor o menor medida está condicionado en este paradigma por una acción catastrófica, ya sea ésta simbólica o palpable.

Las interrogantes que serán el eje de este ensayo, justamente tienen un vínculo directo con la idea anteriormente expuesta. ¿Cuál fue el rol que jugaron las prácticas de tortura y el porqué de su institucionalización en la dictadura chilena entre 1973-1990? Son dos preguntas válidas para tratar de comprender la cara más horrible y oculta de una dictadura: la violación sistemática de los Derechos Humanos a través de métodos tendientes a provocar temor, dolor y silencio.

Este trabajo no busca dar una respuesta definitiva a este problema, sino esbozar algunos conceptos que sirvan para la comprensión de este episodio lamentable en la historia de Chile.

\section{¿Derecho a la vida o a la muerte?}

Para comenzar este ensayo, es necesario realizar un breve paso por el trabajo desarrollado por el francés Michel Foucault, quien plantea que antiguamente el derecho de vida o muerte, independiente de qué sociedad fuera -moderna o antiguasiempre se caracterizaba por ser disimétrico. "El soberano no ejerce su derecho sobre la vida sino poniendo en acción su derecho de matar, o reteniéndole; no indica su poder sobre la vida sino en virtud de la muerte que puede exigir" (Foucault, 1986: 164).

En la actualidad, la denominada potencia de la muerte a la que se refiere Foucault, que representaba el poder y el mando del soberano, ha tenido un proceso inverso porque, por una parte, asegura la administración de los cuerpos y, por otra, gestiona la vida.De acuerdo a lo trazado por el autor, los elementos se encontraban en todos los niveles, de modo tal que actuaron como "factores de segregación y 


\section{SEe \\ SOCIEDADEEQUIDAD}

jerarquización sociales (...), garantizando relaciones de dominación y efectos de hegemonía" (Foucault, 1986: 171). A lo anterior se suma el protagonismo que adquieren las normas a través de un sistema jurídico potente, el cual quedó sellado en la Constitución política de 1980.

Para asegurase que los ciudadanos respetaran estas indicaciones, los militares se apoyaban en la ley, puesto que ésta no puede no estar armada, y su arma por excelencia es la muerte a quienes la transgreden, dice Foucault. No obstante, aquí hay un punto fundamental entregado por el autor en torno al tema del poder, que radica en la tarea de éste: ¿Qué ocurre si la labor del poder es justamente tomar la vida? (Foucault, 1986). La respuesta no es otra que la necesidad de generar diferentes mecanismos continuos y reguladores, que aseguren la concreción de esta tarea. Pero estas herramientas deben caracterizarse por ser de índole correctivo, es decir, prácticas lo suficientemente intensas que generen una intervención y que dobleguen la voluntad del cuerpo que es expuesto a este tipo de manifestación.

Lo anterior quedó enunciado en el Diario Oficial el 18 de septiembre de 1973, donde se publicó el Decreto de Ley $\mathrm{N}^{\circ} 1$ en el cual se expresaba la necesidad de "restaurar la chilenidad, la justicia y la institucionalidad quebrantadas" (Decreto de Ley $\mathrm{N}^{\circ} 1$, 1973). Ante este enunciado, no se tornan extrañas las acciones realizadas para cumplir con este objetivo, lo que no quiere decir que éstas hayan sido las más pertinentes para cumplir con el fin.

\section{La tortura como mecanismo}

Para aspirar a la recuperación de la chilenidad era necesario ejecutar algunas acciones, como la tortura. Este proceso tuvo tres objetivos: conseguir información rápida para realizar procesos de detención y desbaratar actividades subversivas, quebrar la resistencia de los detenidos y castigar su ideología (Rojas, 1988).

La periodista Naomi Klein postula la tortura no solo como una herramienta utilizada para la imposición de reglas, sino que -además- la metáfora de la lógica que subyace en su propuesta de trabajo: la doctrina del shock. Entenderemos por tortura un conjunto de técnicas diseñadas para colocar al prisionero en un estado de profunda desorientación y shock, con el fin de obligarlo a hacer concesiones contra su voluntad (Klein, 2007: 23).

En la dictadura chilena podemos identificar diferentes etapas en la aplicación de los mecanismos de violencia: por una parte, hay una fase inicial donde se promueve el terror a toda la población, visibilizando los centros de detención y tortura a través de un proceso de detenciones masivas. Un claro ejemplo fue la situación vivida por instituciones como la Universidad de Chile o la Universidad Técnica del Estado, en donde ésta última fue duramente sancionada por la Dictadura. Perdió sus sedes regionales y parte de sus alumnos, académicos, 


\section{SEe}

funcionarios y también su nombre, el que era un registro no solo reconocido, sino que también valorado antes del 11 de septiembre de 1973.

De ese día se puede recoger el siguiente relato: "La Universidad es rodeada por un fuerte contingente de carabineros y un gran despliegue de efectivos del Ejército con equipamiento de guerra (...). Hay en el sector de la Casa Central más de mil funcionarios, académicos y estudiantes. Están en el plantel la mayoría de las autoridades, responsables académicos y administrativos que pudieron llegar" (Tiempos de dolor, 1999: 8).

Los integrantes de la UTE pasaron la noche en el lugar, con la promesa de que el 12 de septiembre a las 12.00 desalojarían la institución y serían dirigidos a cuatro puntos de la capital para retornar a sus casas. Sin embargo, todos fueron llevados al Estadio Chile ${ }^{2}$ del cual algunos pudieron salir, mientras que para otros se transformó en una de las tantas moradas donde los cuerpos de los detenidos quedaron expuestos para posteriormente desaparecer y ser borrados del país.

Una segunda etapa tiene que ver con la tortura física y la sustracción de los cuerpos a los que fueron sometidas las mujeres y hombres víctimas de la dictadura dirigida por Pinochet. Más arriba se mencionó la incorporación del cuerpo como un concepto relevante en la comprensión del orden social, traspasando la comprensión meramente biológica que se le asignaba, es decir, éste adquiere vida y sustento por sí mismo más allá de la naturaleza que lo circunscribe en una determinada raza y especie -en este caso-la humana.

La visualización de los cuerpos y el horror de la tortura pueden evidenciarse en el caso del estudiante y dirigente de la sede de Antofagasta de la UTE, Alan Rodríguez Pacheco, quien fue muerto el 3 de enero de 1985. El 21 de septiembre de 1973 fue detenido por Carabineros y transferido al Consejo de Guerra, donde sobreseyeron su causa. Se fue a estudiar a Inglaterra, pero a su regreso volvió a vivir el horror: "Los brazos los tenía rajados como si hubieran querido extraerle los huesos; el cráneo estaba abierto, la cara muy quemada, difícilmente reconocible. Solo me permitieron ver la cabeza, brazos y parte del tórax" (Tiempos de dolor, 1999: 19).

En el cuerpo del estudiante quedó escrita a fuego y sangre una dinámica propia de las dictaduras, que no es otra que la utilización de las catástrofes y los espacios de tortura como un instrumento para lograr el avance e instauración de un tipo de modelo cada vez más deshumanizado.

\footnotetext{
${ }^{2}$ El Estadio Chile (hoy Estadio Víctor Jara) fue utilizado como centro de detención y tortura durante la dictadura militar.
} 


\section{sce}

En ese sentido, la tortura era consustancial al régimen. Tomás Moulian señala que la dictadura militar chilena fue impersonal. "El terror es una necesidad absoluta del poder total, la crueldad es solamente una subjetividad funcional, sin cuya existencia el terror sería irrealizable" (Moulian, 1998:177).

Por su parte, Naomi Klein establece que este tipo de prácticas, que generan un tipo de trauma colectivo y la anulación de las reglas del juego, son necesarias para la aplicación en plenitud de esta "doctrina del shock", que permite establecer y mantener en el tiempo un régimen político sin el apoyo ni legitimidad social (Klein, 2007: 15).

Una tercera instancia es la desaparición de los cuerpos. En la experiencia chilena hubo muchos casos donde los cuerpos sustraídos jamás se encontraron. La UTE-USACH no estuvo al margen de esta vivencia, teniendo entre sus filas varias historias cuyo eje gira en torno a la ausencia del cuerpo y la imposibilidad de materializar la pérdida. Este fue parte del proceso que vivió la familia de Gregorio Mimica; la falta de la materialidad corporal impedía la vivencia del duelo y extendía las heridas y los traumas.

Rina Argote, madre del joven de nacionalidad argentina, declaró ante notario lo acaecido. “El día 14 de septiembre de 1973, recién había llegado mi hijo después de haber estado detenido en el Estadio Chile donde el 12 del mismo mes, se presentó a mi casa una patrulla militar a buscarlo. Al preguntar por qué se lo llevaban, dijeron que era pedido por el Ministerio del Interior y se lo llevaron. Desde ese día no he podido saber nada de la suerte de mi hijo (...)" (Tiempos de dolor, 1999: 22).

La sustracción del cuerpo de Gregorio fue un proceso doloroso, como probablemente se repitió en muchas familias que fueron expuestas a la tortura, muerte y vacío provocado por la falta de un lugar donde llorar a sus seres queridos. ¿Pero fue posible que el tiempo otorgara una respuesta más digna a tanto sufrimiento? Fueron 37 años de incertidumbre los que pasaron antes de que el "Goyo" -como lo nombraban sus amigos- pudiera salir de las sombras. En abril de 2011 el juez Alejandro Solís dio a conocer el hallazgo del cuerpo del estudiante de la UTE, el que se encontró en una fosa común en el patio 29 del Cementerio General.

La tortura en sus más diversas formas de expresión no es sino un claro retroceso del concepto de Derechos Humanos, el cual se posicionó tres años después del fin de la II Guerra Mundial. El 10 de diciembre de 1948 "la Asamblea General de las Naciones Unidas proclamó la Declaración Universal de Derechos Humanos como ideal común por el que todos los pueblos y naciones deben esforzarse, a fin de que tanto los individuos como las instituciones, inspirándose constantemente en ella, promuevan, mediante la enseñanza y la educación, el respeto a estos derechos y libertades, y aseguren, por medidas progresivas de carácter nacional e internacional, su reconocimiento y aplicación universales y efectivos, tanto entre los pueblos de los 


\section{SEe \\ Sresenow}

Estados Miembros como entre los de los territorios colocados bajo su jurisdicción" (Declaración Universal: 1948).

Claramente, esta exposición de nobles ideas, dejó mucho que desear en la dictadura militar, pues en el posicionamiento de ésta se anularon una serie de garantías grupales e individuales, dejando los cuerpos expuestos a la barbarie y la brutalidad.

\section{Anestesia, pero no para todos}

La institucionalización de las prácticas de tortura, cometidas en contra de los estudiantes de la UTE-USACH y contra miles de chilenos, deja en evidencia la dualidad de la anestesia. Esta idea tiene que ver con quiénes son dignos de su aplicación y quiénes son los llamados a sufrir su ausencia.

Por una parte, están todos los cuerpos arrebatados y mutilados por la Dictadura; todas aquellas personas que sufrieron en mayor o menor medida las prácticas empleadas por el régimen, para lograr la subordinación o aniquilación. Esos cuerpos no tuvieron la fortuna de ser inyectados y anestesiados para evadir el dolor. La presencia del sufrimiento y los padecimientos les permitían concretar sus objetivos: quebrantar la dignidad, corroer los ideales y destruir a ese enemigo interno, que se materializaba en los cuerpos de todas aquellas personas que modulaban un discurso distinto al del régimen.

A mediados del siglo XIX, según expone en su trabajo Alain Brossat (2008), es donde surgen las técnicas anestésicas que permiten la insensibilidad de modo artificial, basándose en el saber científico. Sin embargo, este conocimiento también es aplicado para establecer macabras herramientas tendientes a exacerbar el dolor.

La idea anterior constituye lo que Brossat denomina el proceso de reseccionamiento de la humanidad, por el cual habría personas que no tienen garantías. Producto de esto es que los cuerpos estarían en un estado de simpleza, quedando expuestos a los ataques que lleva consigo la modernidad. No obstante, la aparición de la anestesia moderna posiciona un nuevo paradigma civilizatorio: “Con la anestesia moderna se abre una nueva configuración: ya no se trata solamente de disminuir los dolores, sino de crear estados de insensibilidad predecibles (...)" (Brossat, 2008: 56).

Recuperando lo anteriormente señalado, se puede establecer el uso de la anestesia no solo en instancias democráticas sino también en procesos que se erigen en un opuesto constante, como lo son las dictaduras. En la dictadura chilena, encontraremos dos grupos: los anestesiados y los no anestesiados. Los primeros acceden a este instrumento pero no precisamente para suprimir el dolor, sino para perpetrar estados de letargo e inconsciencia, lo que se sustenta y potencia a través de los medios de comunicación. 


\section{SEe}

Por ejemplo, la Dirección de Inteligencia Nacional (DINA) utilizó la televisión como un medio más para desarrollar sus actividades. "Para ello organizó purgas al interior de las estaciones, infiltró agentes y orquestó campañas de desinformación sobre las violaciones de los Derechos Humanos" (La Nación, 2006). A estos cuerpos, los avances alcanzados por la medicina a través de un saber científico asegurado, les permitieron evadir los trances amargos a tal punto de no ser capaces de identificar la irracionalidad bajo la cual se actuó en la Dictadura.

Esos espacios de enajenamiento representaron a muchos chilenos, afectados profundamente por la anestesia. Un caso llamativo es del ex juez, Juan Guzmán Tapia, quien en el documental "El Juez y el General”, del cineasta chileno Patricio Lanfranco y la estadounidense Elizabeth Farnsworth, va teniendo una apertura reflexiva y un cambio en su modo de ver la Dictadura.

En el transcurso de la cinta, el juez reconoce que, al igual que como ocurrió con muchos chilenos, estuvo inmerso en una burbuja, desconociendo la realidad de estos otros cuerpos: los detenidos, desaparecidos, mutilados y usurpados. La periodista Mónica González ratifica en el relato el desconocimiento inicial que tuvo Guzmán Tapia respecto a los crímenes que se cometían en la dictadura chilena. La comunicadora señala que él "creó su propia carpa y se sumergió en su casa (...), tuvo la suerte de no ser violentado y obligado a enfrentarse a esa realidad" (Lanfranco, Famsworth, 2008).

En la primera parte, la relación del juez Guzmán Tapia y la violación a los Derechos Humanos, muestra su etapa de letargo, la cual fue provocada por un estado de anestesia emanado desde su propia psique, como lo plantea Remo Bodei: "Una vez caída la barrera inmunitaria de nuestra psique, la angustia arcaica flota quizás actualmente en nuestra conciencia a la manera de minas flotantes, que rara vez producen daño porque buscamos desactivar la peligrosidad dejándola vagar por una vasta superficie de indiferencia. Los malestares no son mayores o menores respecto del pasado: nos hemos vuelto sin embargo más insensibles a ellos: el malestar circula clandestinamente, como algo de lo que, por sí mismo, no deseamos permanecer cerca" (Bodei, 2005: 44).

Lamentablemente, no todas las personas tuvieron la posibilidad de vivir el proceso reflexivo por el cual el ex juez Juan Guzmán Tapia, pudo aclarar sus dudas y llenar los vacíos respecto a esta parte de la historia de Chile. Los que ignoraban la realidad, tuvieron una dosis de anestesia mayor que la dosis de conciencia, posibilitando sus efectos a nivel de paradigma civilizatorio y con ello, asumiendo las consecuencias en serie que acarreaba una jeringa con un líquido proporcionado por el conocimiento científico: para unos, la privación del dolor y la violencia a través de la invención constante de dispositivos como son los medios de comunicación, mientras para otros propició la exposición absoluta. 


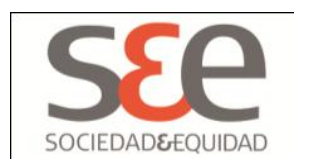

\section{Conclusiones}

De este ensayo se pueden extraer variadas ideas. Primero, las dictaduras militares se valen del uso de la fuerza y de las prácticas coercitivas para institucionalizarse. Lo anterior lo consiguen a través de una sistemática violación a los Derechos Humanos.

Bajo el término de tortura se esconden diversas prácticas represivas, que tienen por finalidad difuminar las ideas y los cuerpos que giran en torno a los discursos que podrían clasificarse como enemigos internos, en tanto estos no reproducen a voluntad un modelo represivo.

Tras la ruptura de los cuerpos y las lecciones de poder, es necesario atar todas las ideas propugnadas por el nuevo régimen a través de normas. El posicionamiento de un nuevo modelo -independiente de su naturaleza política, económica, social o cultural- requiere generar un daño profundo que haga un quiebre con la anterior institucionalidad, permitiéndole afectar los más diversos espacios de la vida, los cuerpos y su movilidad.

En el caso chileno, se traduce en un ladrillo constitucional que ató e impidió el avance en temas significativos como la salud, sexualidad y educación, que si bien asumen un espacio de decisión para las personas, ésta es mínima y reducida a los márgenes de acción que la ley valida, es decir, un espacio cuya normativa es restrictiva para las personas y coercitiva para los cuerpos.

Finalmente, es necesario reiterar la irregularidad de la aplicación de la anestesia, pues su utilización no está asegurada para todas las personas, menos estando frente a procesos dictatoriales que toman entre sus manos el fundamento del dolor y la provocación de éste para validarse y perpetuarse. En ese sentido, nos encontraremos que en Chile el régimen realizó una segregación y división de los individuos y sus cuerpos. Los que fueron rodeados por el manto de silencio, por verdadero desconocimiento -la televisión y los medios de comunicación escritos jugaron un rol central en este estado de desinformación- o por decisión propia, propiciado por posturas ideológicas afines al régimen, que negaban cualquier atisbo de represión, fueron a quienes se les permitió adquirir la dosis de anestesia necesaria para continuar su vida y su caminar de acuerdo a los parámetros establecidos.

En cambio, todos aquellos que fueron clasificados en el otro bando debieron someterse al dolor, pues no se les permitió acceder a la anestesia. No fueron adormecidos, sino que a sus cuerpos se infligió mucho sufrimiento para silenciarlos. Esta fue la experiencia de muchos de los estudiantes, profesores y académicos de la Universidad Técnica del Estado. Considero pertinente recordar cada cierto tiempo estos trances, revivir estos cuerpos y darles un hálito de vida para que al menos exista un registro de su tránsito por este país y estas calles. 


\section{S\&e}

\section{Referencias Bibliográficas}

Bodei, Remo (2005). El doctor Freud y los nervios del alma. Filosofía y sociedad a un siglo del nacimiento del psicoanálisis. $1^{\text {a }}$.Ed. Buenos Aires: Siglo XXI Editores.

Brossat, Alain (2008). Democracia Inmunitaria. Santiago: Editorial Palinodia.

Centro Pastoral Universitaria USACH (1999). Tiempo de dolor, tiempo de esperanza...: los derechos humanos en UTE-USACH 1973-1989. Santiago, $2^{\text {a }}$ Edición.

Esposito, Roberto (2005). Immunitas. Protección y negación de la vida. Buenos Aires: Amorrortu.

Foucault, Michel (1986). Derecho de muerte, de vida y poder sobre la vida, Historia de la sexualidad. La voluntad del saber. México: Siglo XXI.

Fuenzalida, Christian (2006). 17 años de Cadena Nacional. La Nación. Recuperado 14-11-2011 en

<http://www.lanacion.cl/noticias/site/artic/20061230/pags/20061230184025.html>

Klein, Naomi (2007). La Doctrina del shock. Barcelona: Paidos.

Lanfranco, Patricio y Farnsworth, Elizabeth (2008). El Juez y el General [videograbación]. Estados Unidos y Chile.

Naciones Unidas (s.a). Declaración Universal de los Derechos Humanos. Recuperado 04-07-2011 en < http://www.un.org/es/documents/udhr/index.shtml>

Rojas, María Eugenia (1988). La represión política en Chile. Madrid: lepala Editorial. 